\title{
APPLICATION OF APPARENT IMPEDANCE METHOD AT VARIABLE SPECIFIC RESISTANCE OF PHASE CONDUCTOR
}

\author{
J. Survilo \\ Riga Technical University \\ Kronvalda blv. 1, LV 1010, Riga, LATVIA
}

\begin{abstract}
The apparent impedance to single-phase earth fault place is obtained applying the classical algorithm of distance protection. Thanks to a complex character of this impedance, the expression for the algorithm decomposes into two equations, allowing two unknowns to be calculated: the reactance to a fault place and the fault resistance, provided the faulty phase voltage and current as well as ground current or zero sequence current are known. To do this, a special mathematical procedure called here the apparent impedance method is employed, which implies the use of specific line parameters. For high voltage two-terminal and radial lines of distribution networks the iterative procedure could be applied under the condition that the faulty phase voltage is measured in a distribution network with sufficient precision. Among other specific line parameters, the inconsistency of specific resistance of the phase conductor deserves special attention because of its unpredictable nature and wide range of deviations causing inadmissible errors in distribution networks. To cope with this shortcoming, the temperature of the phase conductor wire should be known at the moment of fault inception. Otherwise, the single-phase earth fault current should be increased to the level above the half the line load current.
\end{abstract}

Key words: distance protection, fault resistance, high voltage network, medium voltage grid, single-phase earth fault.

\section{INTRODUCTION}

Protection of two-terminal power lines in the case of single-phase earth fault using one-terminal fault data has been given much attention for a long time. For this purpose, various methods based on digital technique have been proposed [13]. Special methods, such as frequency allocation and analysis of initial voltages, requiring however additional technical means, are applied to locate such a fault [4]. Even a neural artificial network can be used to achieve advantageous results $[5,6]$.

In 2004, an attempt was made [7] to apply the classical algorithm of distant protection for determination of the direct sequence reactance $X_{1}$ to a single-phase earth fault place:

$$
\dot{Z}_{a}=\frac{\dot{U}_{p h}}{\dot{I}_{p h}+\dot{K}_{N} \dot{I}_{g}},
$$

where $\dot{Z}_{a}$ is the apparent impedance to fault place; $\dot{K}_{N}$ is a compensation coefficient; $\dot{U}_{p h}$ is the faulty phase voltage; $\dot{I}_{p h}$ is the faulty phase current; $\dot{I}_{g}$ is the ground current. 
Afterwards this way of handling apparent impedance $\dot{Z}_{a}$ (called here "apparent impedance method") was accomplished for single lines [8]. Later on, the method was adapted for double circuit (parallel) lines [9]. The authors of [10] applied the method for distribution networks with small single-phase earth currents. Similar methods found use in the case of two-terminal lines for other types of short circuits [11]. The purpose of this paper is to consider the possibility to apply the apparent impedance method for high- and medium-voltage networks in the cases when the active resistance of the phase conductor of a power line is difficult to predict. Besides, the theory of the mentioned method is expounded here more coherently than it was made in [7-10].

Applying the apparent impedance method, the configuration of power line is implied to be symmetrical or effectively transposed. This condition must be met to avoid significant errors.

\section{THE THEORY AND THE METHOD}

To determine the apparent impedance $\dot{Z}_{a}$ in accordance with (1), it is necessary to measure faulty phase voltage $\dot{U}_{p h}$, faulty phase current $\dot{I}_{p h}$, and ground current $\dot{I}_{g}$ at the place of installation of a protection device (at the monitoring point). Besides, to take into account the dissimilarity of positive and zero sequence impedances of a power line, a compensation coefficient $\dot{K}_{N}$ should be calculated:

$$
\dot{K}_{N}=\frac{1}{3} \frac{\dot{Z}_{0}-\dot{Z}_{1}}{\dot{Z}_{1}}=\frac{1}{3} \frac{\dot{Z}_{0 s p}-\dot{Z}_{1 s p}}{\dot{Z}_{1 s p}},
$$

where $\dot{Z}_{0} ; \dot{Z}_{1}$ are the zero sequence and positive sequence impedances to the fault place; respectively, $\dot{Z}_{0 s p} ; \dot{Z}_{1 s p}$ are corresponding specific quantities which are supposed to be known for a power line under consideration.

In this section it will be shown how the required positive sequence reactance $X_{I}$ to the fault place can be determined using the calculated by Eq. (1) apparent impedance quantity $\dot{Z}_{a}$.

The modern microprocessor technique makes it possible to find apparent impedance $\dot{Z}_{a}$ and its real $R_{a}$ and imaginary $X_{a}$ components with the necessary precision:

$$
R_{a}=\operatorname{Re}\left(\frac{\dot{U}_{p h}}{I_{p h}+\dot{K}_{N} \dot{I}_{g}}\right) ; \quad X_{a}=\operatorname{Im}\left(\frac{\dot{U}_{p h}}{I_{p h}+\dot{K}_{N} \dot{I}_{g}}\right) .
$$

To clarify the matter, let us consider the circuit diagram in Fig. 1. For the sake of generalization, the neutral is closed through the earthing impedance. Positive, negative and zero sequence impedances $\dot{Z}_{1}, \dot{Z}_{2}$, and $\dot{Z}_{0}$ to a fault place and corresponding specific quantities are the following:

$$
\begin{array}{ll}
\dot{Z}_{1}=\dot{Z}_{2}=\dot{Z}_{1 s p} l=R_{c}+j X_{1} ; & \dot{Z}_{0}=\dot{Z}_{0 s p} l=R_{0}+3 R_{g}+j X_{0} ; \\
\dot{Z}_{1 s p}=\dot{Z}_{2 s p}=R_{c s p}+j X_{1 s p} ; & \dot{Z}_{0 s p}=R_{0 s p}+3 R_{g s p}+j X_{0 s p},
\end{array}
$$


where $R_{c}$ is the active resistance of phase conductor; $R_{0}$ is the zero sequence active resistance of phase conductor; $R_{g}$ is the ground resistance; $X_{1}, X_{0}$ are the direct and zero sequence reactances; $l$ is the distance from the monitoring point to the fault place; $R_{c s p}, R_{0 s p}, R_{g s p}, X_{1 s p}, X_{0 s p}$.are the specific parameters.

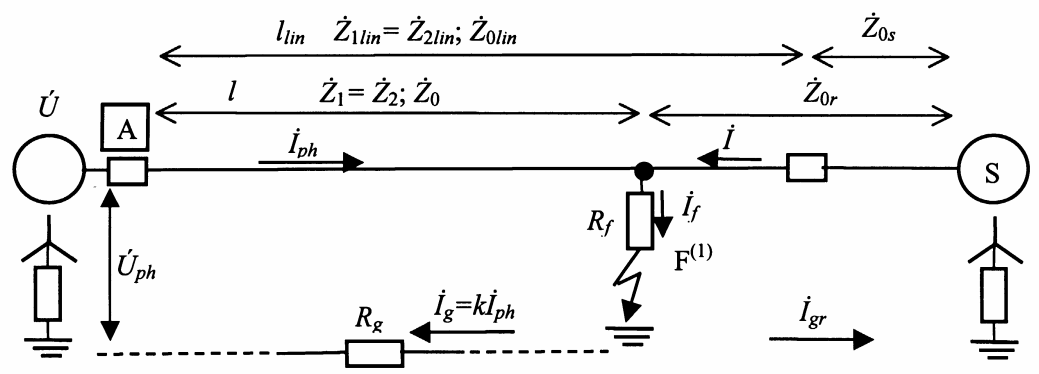

Fig.1. Circuit diagram of the line faulty phase

A - protection device; $\dot{U}$ - phase voltages at the point of its installation; $R_{f}$ - fault resistance (between the faulty phase wire and the earth); $\mathrm{F}^{(1)}$ - single-phase earth fault; $\mathrm{S}$ - electric system at the far end of the line; $l_{\text {lin }}$ and $l$-power line length and distance to the fault place, $\mathrm{km} ; \dot{Z}$ - corresponding impedances.

The quantities $R_{c}, R_{0}, R_{g}, X_{1}, X_{0}$ in (4) are expressed by the products:

$R_{c}=R_{c s p} l ; \quad R_{0}=R_{0 s p} l ; \quad R_{g}=R_{g s p} l ; \quad X_{1}=X_{1 s p} l ; \quad X_{0}=X_{0 s p} l$.

Faulty phase current $\dot{I}_{p h}$, according to Fortescue's method [12], consists of positive $\dot{I}_{1 l}$, negative $\dot{I}_{21}$ and zero $\dot{I}_{0 l}$ sequence currents:

$\dot{I}_{p h}=\dot{I}_{1 l}+\dot{I}_{2 l}+\dot{I}_{0 l}$,

with the following dependence valid:

$\dot{I}_{g}=3 \dot{I}_{0 l}$.

We can measure ground current $\dot{I}_{g}$ or calculate current $I_{0 l}$ using known Fortescue's formulas by three phase currents $\left(\dot{I}_{A} ; \dot{I}_{B} ; \dot{I}_{C}\right)$ measured by phase current transformers. Therefore we can determine current quotient $\dot{k}$ and its real $k^{\prime}$ and imaginary $k^{\prime \prime}$ parts:

$\dot{k}=\frac{\dot{I}_{g}}{\dot{I}_{p h}}=\frac{3 \dot{I}_{0 l}}{\dot{I}_{p h}}=k^{\prime}+j k^{\prime \prime} ; \quad k^{\prime}=\operatorname{Re}(\dot{k}) ; \quad k^{\prime \prime}=\operatorname{Im}(k)$.

Hence

$\dot{I}_{0 l}=\frac{\dot{k}}{3} \dot{I}_{p h} ; \quad \dot{I}_{1 l}+\dot{I}_{2 l}=\frac{3-\dot{k}}{3} \dot{I}_{p h}$.

The expression for faulty phase voltage $\dot{U}_{p h}$ can be written as

$\dot{U}_{p h}=\dot{I}_{1 l} \dot{Z}_{1}+\dot{I}_{2 l} \dot{Z}_{2}+\dot{I}_{0 l} \dot{Z}_{0}+\dot{I}_{f} R_{f}=\left(\dot{I}_{1 l}+\dot{I}_{2 l}\right) \dot{Z}_{1}+\dot{I}_{0 l} \dot{Z}_{0}+\dot{k}_{f} R_{f}$. 
Fault current $\dot{I}_{f}$ may be or may not be equal to ground current $\dot{I}_{g}$. Further, this question will be concretized. The relation between phase current $\dot{I}_{p h}$ and fault current $\dot{I}_{f}$ is determined by quotient $\dot{k}_{f}$ and its real $k_{f}^{\prime}$ and imaginary $k_{f}^{\prime \prime}$ components:

$\dot{k}_{f}=\frac{\dot{I}_{f}}{\dot{I}_{p h}}=k_{f}^{\prime}+j k_{f}^{\prime \prime} ; \quad k_{f}^{\prime}=\operatorname{Re}\left(\dot{k}_{f}\right) ; \quad k_{f}^{\prime \prime}=\operatorname{Im}\left(\dot{k}_{f}\right)$.

Now, let us define the so-called putative ground resistance $R_{g p}$ for power lines where zero sequence active resistance $R_{0}$ of the phase conductor differs from its the positive and negative sequence active resistance $R_{c}$ :

$$
R_{g p}=\frac{R_{0}-R_{c}}{3}+R_{g}
$$

When $R_{c}$ and $R_{0}$ of a power line do not differ, the following is true:

$$
R_{g p}=R_{g} ; \quad R_{g p s p}=R_{g s p} .
$$

Using (12) and observing (4); (9) and (11), we can rewrite expression (10) for phase voltage $\dot{U}_{p h}$ :

$$
\dot{U}_{p h}=\dot{I}_{p h}\left\{\left(R_{c}+\dot{k} R_{g p}+\dot{k}_{f} R_{f}\right)+j \frac{1}{3}\left[(3-\dot{k}) X_{1}+\dot{k} X_{0}\right]\right\} .
$$

The resistances and reactances are shown in Fig. 1. In the simplest case, when: 1) the total phase current $\dot{p}_{p h}$ flows through a fault place and along the ground path ( $\dot{I}_{p h}=\dot{I}_{g}$, hence $\dot{k}=1$ and $\left.\dot{k}_{f}=1\right)$, and 2) there is no fault resistance $\left(R_{f}=0\right)-$ the real and imaginary parts of expression (14) become simpler and could be designated $R_{S}$ and $X_{s}$ :

$$
\begin{aligned}
& R_{s}=R_{c}+\dot{k} R_{g p}+\dot{k}_{f} R_{f}=R_{c}+R_{g p} ; \\
& X_{s}=\frac{1}{3}\left[(3-\dot{k}) X_{1}+\dot{k} X_{0}\right]=\frac{1}{3}\left(2 X_{1}+X_{0}\right) .
\end{aligned}
$$

Having denoted:

$$
\begin{aligned}
& \dot{k}_{R}=\frac{R_{c}+\dot{k} R_{g p}+\dot{k}_{f} R_{f}}{R_{s}}=k_{R}^{\prime}+j k_{R}^{\prime \prime} ; \quad k_{R}^{\prime}=\operatorname{Re}\left(\dot{k}_{R}\right) ; \quad k_{R}^{\prime \prime}=\operatorname{Im}\left(\dot{k}_{R}\right) ; \\
& \dot{k}_{X}=\frac{(3-\dot{k}) X_{1}+\dot{k} X_{0}}{3 X_{s}}=k_{X}^{\prime}+j k_{X}^{\prime \prime} ; \quad k_{X}^{\prime}=\operatorname{Re}\left(\dot{k}_{X}\right) ; \quad k_{X}^{\prime \prime}=\operatorname{Im}\left(\dot{k}_{X}\right)
\end{aligned}
$$

( $k_{R}^{\prime} ; k_{X}^{\prime}$ are the real parts and $k_{R}^{\prime \prime} ; k_{X}^{\prime \prime}$ - the imaginary ones) we can rewrite expression (14) as 


$$
\dot{I}_{p h}=\frac{\dot{U}_{p h}}{\dot{k}_{R} R_{s}+\dot{k}_{X} X_{s}} .
$$

Now expression (1), taking into account (2) and (17), will be written as:

$$
\dot{Z}_{a}=\left(R_{c}+j X_{1}\right) \frac{\dot{k}_{R} R_{s}+\dot{k}_{X} X_{s}}{\dot{k}_{d R} R_{s}+\dot{k}_{d X} X_{s}}
$$

where complex coefficients $\dot{k}_{d R} ; \dot{k}_{d X}$ (and their real $k_{d r}^{\prime}$ and imaginary $k_{d r}^{\prime \prime}$ parts) are:

$$
\begin{aligned}
& \dot{k}_{d R}=\frac{R_{c}+\dot{k} R_{g p}}{R_{s}}=k_{d R}^{\prime}+j k_{d R}^{\prime \prime} ; \\
& \dot{k}_{d X}=\frac{(3-\dot{k}) X_{1}+\dot{k} X_{0}}{3 X_{s}}=k_{d X}^{\prime}+k_{d X}^{\prime \prime} .
\end{aligned}
$$

When faulty phase voltage $\dot{U}_{p h}$ can be expressed by (14), it is obvious that

$$
\dot{k}_{d X}=\dot{k}_{X} .
$$

The protection device, having at its input phase current $\dot{I}_{p h}$, phase voltage $\dot{U}_{p h}$ and ground current $\dot{I}_{g}$ (which can be replaced by current $\dot{I}_{0 l}$ ), computes by expression (1) apparent impedance $\dot{Z}_{a}$ and its real $R_{a}$ and imaginary $X_{a}$ components in accordance with (3), provided compensation coefficient $\dot{K}_{N}$ is found by Eq. (2) out of $\dot{Z}_{1}$ and $\dot{Z}_{0}$.

From (18), having obtained $R_{a}$ and $X_{a}$ by (3), we can determine the soughtfor values of $X_{I}$ (which is equivalent to the distance to a fault place) and fault resistance $R_{f} \geq 0$ as follows.

At the beginning, the real part of expression (18) must be rewritten in a concise pattern as

$$
R_{a}=R_{c} V-X_{1} W,
$$

from where $V$ and $W$ could be presented as

$$
\begin{aligned}
V & =\frac{\left(k_{R}^{\prime} k_{d R}^{\prime}+k_{R}^{\prime \prime} k_{d R}^{\prime \prime}\right) R_{s}^{2}}{\left(k_{d R}^{\prime 2}+k_{d R}^{\prime \prime 2}\right) R_{s}^{2}+2\left(k_{d R}^{\prime \prime} k_{d X}^{\prime}-k_{d R}^{\prime} k_{d X}^{\prime \prime}\right) R_{s} X_{s}+\left(k_{d X}^{\prime 2}+k_{d X}^{\prime \prime 2}\right) X_{s}^{2}}+ \\
& +\frac{\left[\left(k_{X}^{\prime} k_{d R}^{\prime \prime}+k_{R}^{\prime \prime} k_{d X}^{\prime}\right)-\left(k_{X}^{\prime \prime} k_{d R}^{\prime}+k_{R}^{\prime} k_{d X}^{\prime \prime}\right)\right] R_{s} X_{s}}{\left(k_{d R}^{\prime 2}+k_{d R}^{\prime \prime 2}\right) R_{s}^{2}+2\left(k_{d R}^{\prime \prime} k_{d X}^{\prime}-k_{d R}^{\prime} k_{d X}^{\prime \prime}\right) R_{s} X_{s}+\left(k_{d X}^{\prime 2}+k_{d X}^{\prime \prime 2}\right) X_{s}^{2}}+ \\
& +\frac{\left(k_{X}^{\prime} k_{d X}^{\prime}+k_{X}^{\prime \prime} k_{d X}^{\prime \prime}\right) X_{s}{ }^{2}}{\left(k_{d R}^{\prime 2}+k_{d R}^{\prime \prime 2}\right) R_{s}^{2}+2\left(k_{d R}^{\prime \prime} k_{d X}^{\prime}-k_{d R}^{\prime} k_{d X}^{\prime \prime}\right) R_{s} X_{s}+\left(k_{d X}^{\prime 2}+k_{d X}^{\prime \prime}\right) X_{s}{ }^{2}}
\end{aligned}
$$




$$
\begin{gathered}
W=\frac{\left(k_{R}^{\prime \prime} k_{d R}^{\prime}-k_{R}^{\prime} k_{d R}^{\prime \prime}\right) R_{s}^{2}}{\left(k_{d R}^{\prime 2}+k_{d R}^{\prime \prime 2}\right) R_{s}^{2}+2\left(k_{d R}^{\prime \prime} k_{d X}^{\prime}-k_{d R}^{\prime} k_{d X}^{\prime \prime}\right) R_{s} X_{s}+\left(k_{d X}^{\prime 2}+k_{d X}^{\prime \prime 2}\right) X_{s}^{2}}+ \\
+\frac{\left[\left(k_{X}^{\prime} k_{d R}^{\prime}+k_{X}^{\prime \prime} k_{d R}^{\prime \prime}\right)-\left(k_{R}^{\prime} k_{d X}^{\prime}+k_{R}^{\prime \prime} k_{d X}^{\prime \prime}\right)\right] R_{s} X_{s}}{\left(k_{d R}^{\prime 2}+k_{d R}^{\prime 2}\right) R_{s}^{2}+2\left(k_{d R}^{\prime \prime} k_{d X}^{\prime}-k_{d R}^{\prime} k_{d X}^{\prime \prime}\right) R_{S} X_{s}+\left(k_{d X}^{\prime 2}+k_{d X}^{\prime \prime 2}\right) X_{s}^{2}}+ \\
+\frac{\left(k_{X}^{\prime \prime} k_{d X}^{\prime}-k_{X}^{\prime} k_{d X}^{\prime \prime}\right) X_{s}^{2}}{\left(k_{d R}^{\prime 2}+k_{d R}^{\prime \prime 2}\right) R_{s}^{2}+2\left(k_{d R}^{\prime \prime} k_{d X}^{\prime}-k_{d R}^{\prime} k_{d X}^{\prime \prime}\right) R_{s} X_{s}+\left(k_{d X}^{\prime 2}+k_{d X}^{\prime \prime}\right) X_{s}^{2}}
\end{gathered}
$$

The quantities $R_{c}$ and $X_{1}$ are so far unknown. To expand (21) it is necessary to use (22) and the following designations:

$$
\begin{aligned}
& a=\frac{R_{c}}{X_{1}}=\frac{R_{c s p}}{X_{1 s p}} ; \quad b=\frac{R_{s}}{X_{1}}=\frac{R_{c}+R_{g p}}{X_{1}}=\frac{R_{c s p}+R_{g p s p}}{X_{1 s p}} ; \\
& c=\frac{X_{s}}{X_{1}}=\frac{2 X_{1}+X_{0}}{3 X_{1}}=\frac{2 X_{1 s p}+X_{0 s p}}{3 X_{1 s p}},
\end{aligned}
$$

where the quantities in the numerator and denominator are defined by (4), (5), (12), (13) and (15).

Applying designations (22), (23) to expression (21), we obtain a formula for $R_{a}$ with 16 terms in the numerator (represented by “....") and with 6 terms in the denominator:

$$
R_{a}=\frac{\ldots}{\left(k_{d R}^{\prime 2}+k_{d R}^{\prime \prime 2}\right) b^{2}+2\left(k_{d R}^{\prime \prime} k_{d X}^{\prime}-k_{d R}^{\prime} k_{d X}^{\prime \prime}\right) b c+\left(k_{d X}^{\prime 2}+k_{d X}^{\prime \prime 2}\right) c^{2}} .
$$

Having denoted once more:

$$
d^{\prime}=\frac{R_{c s p}+k^{\prime} R_{g p s p}}{X_{1 s p}} ; \quad d^{\prime \prime}=\frac{k^{\prime \prime} R_{g p s p}}{X_{1 s p}}
$$

and using (23), coefficients $k_{R}^{\prime} ; k_{R}^{\prime \prime}$ (see (16)), can be expressed as:

$$
k_{R}^{\prime}=\frac{d^{\prime}}{b}+\frac{k_{f}^{\prime} R_{f}}{b X_{1}} ; \quad k_{R}^{\prime \prime}=\frac{d^{\prime \prime}}{b}+\frac{k_{f}^{\prime \prime} R_{f}}{b X_{1}} .
$$

To make expression (24) more readable, we will introduce additionally the following designations:

$$
\begin{aligned}
& h=\left(k_{d R}^{\prime 2}+k_{d R}^{\prime \prime 2}\right) b^{2}+2\left(k_{d R}^{\prime \prime} k_{d X}^{\prime}-k_{d R}^{\prime} k_{d X}^{\prime \prime}\right) b c+\left(k_{d X}^{\prime 2}+k_{d X}^{\prime \prime 2}\right) c^{2} ; \\
& f^{\prime}=a b k_{d R}^{\prime}-a c k_{d X}^{\prime \prime}+b k_{d R}^{\prime \prime}+c k_{d X}^{\prime} ; \quad f^{\prime \prime}=a b k_{d R}^{\prime \prime}+a c k_{d X}^{\prime}-b k_{d R}^{\prime}+c k_{d X}^{\prime \prime} \\
& \frac{k_{f}^{\prime \prime}}{k_{f}^{\prime}}=\operatorname{tg} \varphi_{f} .
\end{aligned}
$$


Now apparent resistance $R_{a}$ can be written as:

$$
R_{a}=\frac{d^{\prime} f^{\prime}+d^{\prime \prime} f^{\prime \prime}+c\left(k_{X}^{\prime} f^{\prime \prime}-k_{X}^{\prime \prime} f^{\prime}\right)}{h} X_{1}+\frac{\left(f^{\prime}+f^{\prime \prime} \operatorname{tg} \varphi_{f}\right) k_{f}^{\prime}}{h} R_{f} .
$$

Apparent reactance $X_{a}$ can be found in the same manner:

$$
X_{a}=\frac{c\left(k_{X}^{\prime} f^{\prime}+k_{X}^{\prime \prime} f^{\prime \prime}\right)+d^{\prime \prime} f^{\prime}-d^{\prime} f^{\prime \prime}}{h} X_{1}+\frac{\left(f^{\prime} \operatorname{tg} \varphi_{f}-f^{\prime \prime}\right) k_{f}^{\prime}}{h} R_{f} .
$$

From (28) and (29) four coefficients can be separated out:

$$
\begin{aligned}
& A=\frac{d^{\prime} f^{\prime}+d^{\prime \prime} f^{\prime \prime}+c\left(k_{X}^{\prime} f^{\prime \prime}-k_{X}^{\prime \prime} f^{\prime}\right)}{h} ; \quad B=\frac{\left(f^{\prime}+f^{\prime \prime} \operatorname{tg} \varphi_{f}\right) k_{f}^{\prime}}{h} ; \\
& C=\frac{c\left(k_{X}^{\prime} f^{\prime}+k_{X}^{\prime \prime} f^{\prime \prime}\right)+d^{\prime \prime} f^{\prime}-d^{\prime} f^{\prime \prime}}{h} ; \quad D=\frac{\left(f^{\prime} \operatorname{tg} \varphi_{f}-f^{\prime \prime}\right) k_{f}^{\prime}}{h} .
\end{aligned}
$$

In virtue of (20), coefficients $A$ and $C$ become:

$$
A=a ; \quad C=1,
$$

which can be proven applying to (30) expression (20) and using the equalities:

$$
d^{\prime}=k_{d R}^{\prime} b ; \quad d^{\prime \prime}=k_{d R}^{\prime \prime} b,
$$

(for coefficients $a$ and $b$ see (23)).

Equalities (31) are very useful for verification of calculation programs; besides, they allow the final formulas for the sought values $X_{l}$ and $R_{f}$ to be obtained more simply. Namely, from (28)-(31) we find:

$$
\begin{aligned}
& X_{1}=\frac{B X_{a}-D R_{a}}{B-a D}=\frac{\left(f^{\prime}+f^{\prime \prime} \operatorname{tg} \varphi_{f}\right) X_{a}-\left(f^{\prime} \operatorname{tg} \varphi_{f}-f^{\prime \prime}\right) R_{a}}{f^{\prime}\left(1-\operatorname{atg} \varphi_{f}\right)+f^{\prime \prime}\left(\operatorname{tg} \varphi_{f}+a\right)} ; \\
& R_{f}=\frac{R_{a}-a X_{a}}{B-a D}=\frac{h\left(R_{a}-a X_{a}\right)}{k_{f}^{\prime}\left[f^{\prime}\left(1-\operatorname{atg} \varphi_{f}\right)+f^{\prime \prime}\left(\operatorname{tg} \varphi_{f}+a\right)\right]} .
\end{aligned}
$$

After that, the distance $l$ to the fault place can be easily determined:

$$
l=\frac{X_{1}}{X_{1 s p}} .
$$

From (33) it follows distinctly that the positive sequence reactance to fault place $X_{I}$ depends on the apparent resistance $R_{a}$ and apparent reactance $X_{a}$, which are computed by the protection device provided that the fault angle $\varphi_{f}$ is known. This angle can be calculated if current $\dot{I}_{g r}$ (see Fig. 1) is known. For one-terminal line (the line fed from one side) with dead-earthed neutral the current $\dot{I}_{g r}$ can be considered zero, which significantly simplifies calculation by (33). In this case

$$
\dot{k}=\dot{k}_{f}=1 ; \quad \dot{k}_{d R}=\dot{k}_{d X}=1, \quad \operatorname{tg} \varphi_{f}=0
$$


and, consequently,

$$
X_{1}=\frac{f^{\prime} X_{a}+f^{\prime \prime} R_{a}}{f^{\prime}+a f^{\prime \prime}} ; \quad R_{f}=\frac{h\left(R_{a}-a X_{a}\right)}{f^{\prime}+a f^{\prime \prime}} .
$$

In a still more particular case, when there is a metallic fault $\left(R_{f}=0\right)$, we will have:

$$
R_{a}=a X_{a}=R_{c} ; \quad X_{a}=X_{1},
$$

which corresponds to the physical sense of an electrical circuit.

For two-terminal line with dead-earthed neutral the iterative methods must be applied, which allow step-by-step calculation of unknown current $\dot{I}_{r}$ (strictly speaking, the ground current from the right side of the line $\dot{I}_{g r}$ ) [8]. The peculiarities of expressions (33) applied for grids with small single-phase fault currents are considered in [10] (for more correct presentation see Sect. 4 of the present paper).

\section{THE PROPOSED METHOD AT DEVIATIONS OF SPECIFIC QUANTITIES OF A POWER LINE}

The proposed method uses several specific quantities of a power line, namely: $R_{c s p} ; R_{0 s p} ; R_{g s p} ; X_{1 s p} ; X_{0 s p}$ (see (4) and (5)). For the sake of simplicity, the influence of remaining (not mentioned) line parameters is supposed to be too weak and can be ignored. All the mentioned quantities may deviate from the values written in the memory of a protection device due to temperature change or other causes. Their influence on output quantities $X_{l}$ and $R_{f}$ can roughly be accounted for by the differential of these quantities with respect to each of the five specific quantities. As can be seen from the shown above complicated expressions, the conventional mathematical procedure for evaluation of the influence exerted by the mentioned deviations might be considered hopeless. The result can be obtained more quickly applying modern techniques of calculation. Preliminary considerations allow for the statement that only specific active resistance of phase conductor $R_{c s p}$ for direct sequence and specific active resistance of phase conductor $R_{0 s p}$ for zero sequence (in high voltage networks) are of concern, since just these parameters change with temperature as a result of ambient temperature fluctuations and the current in a phase wire at the moment of fault. Indeed, for copper wires the temperature change of $50^{\circ} \mathrm{C}$ causes $20 \%$ change in resistance. At the same time, the other three specific quantities are temperature-stable (or the least instable). On the other hand, digressions of specific parameters as a result of a power line's build-up can be taken into account by measurements or recalculations; however these cannot be applied to the specific resistances $R_{c s p}$ and $R_{0 s p}$ of the conductor because of its unpredictable temperature.

The values of $R_{c s p}$ and $R_{0 s p}$ (as well as other mentioned parameters) are written into the protection device memory. At the time of fault occurrence, the instant actual values of these parameters differ from the written (being, e.g. $R_{c s p}^{\prime}$ and $R_{0 s p}^{\prime}$ ). Naturally enough, the protection device gives out some $X_{1}^{\prime}$ value that deviates from its right value $X_{l}$. If this device deals with actual conductor resistance $R_{c s p}{ }^{a}$ it would give out inerrable positive sequence reactance to fault place $X_{1}$, so the task is to obtain $R_{c s p}{ }^{a}$. In papers $[10,13]$, attempts were made to 
compute the actual value of phase conductor specific active resistance using only voltages and currents at the monitoring point. These attempts, however, turned out to be erroneous; admittedly, the influence of $R_{c s p}$ inconsistency could be diminished only by obtaining, directly or indirectly, this value in another way. For example, this can be calculated as a function of the phase conductor temperature, which depends on the current flowing through the phase conductor and on its ambient temperature.

In turn, the influence exerted by the inconsistency in this parameter depends on the correlation between the single-phase earth fault and load currents. The greater the former is as compared with the latter, the weaker the influence of conductor resistance. Hence, the phase conductor active resistance, to a different extent in high-voltage grids and in medium-voltage ones, influences the accuracy at calculation of the reactance to fault place $X_{l}$.

\section{THE CASE OF HIGH-VOLTAGE NETWORKS}

To a high voltage network the following is inherent:

1) transformer neutrals are dead-earthed, which causes great single-phase earth currents, therefore load currents can be neglected (this feature is of no significance when specific active resistance is known);

2) faulty phase voltage is of the order of sound (undamaged) phase voltage;

3) the line may have a shield wire; as a result, the phase conductor active resistance for positive sequence $R_{c}$ and for zero sequence $R_{0}$ are different.

At the beginning, we will find $X_{I}$ by (33) for the $R_{c s p}$ and $R_{0 s p}$ values written in the protection device and the other three specific quantities.

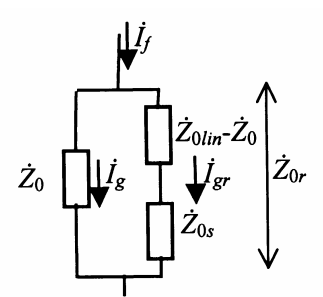

Fig. 2. Estimation of fault current in iterative process.

Based on these specific quantities and on the measured currents $\dot{I}_{p h}$ and $\dot{I}_{g}$ or $\dot{I}_{0}$, the intermediate quantities $h, f^{\prime}$ and $f^{\prime \prime}$ should be calculated. To find the first approximation of $X_{I}^{(l)}$ (and $R_{f}^{(l)}$ ) by (33) using apparent quantities $R_{a}$ and $X_{a}$ given by the protection device, the fault coefficient $\dot{k}_{f}$ must be found (because $k_{f}^{\prime}$ and $\operatorname{tg} \varphi_{f}$ are directly determined by $\dot{k}_{f}$ ). However, to find $\dot{k}_{f}$, the fault current $\dot{I}_{f}$ (being the sum of measured current $\dot{I}_{g}$ and unknown current $\dot{I}_{g r}$ (Fig. 2)) should be known. Considering Figs. 1 and 2, the first approximation for the fault current can be determined as

$$
\dot{I}_{f}{ }^{(1)}=\dot{I}_{g} \frac{\dot{Z}_{0 l i n}+\dot{Z}_{0 s}}{\dot{Z}_{0 r}{ }^{(1)}},
$$

where zero sequence impedance $\dot{Z}_{0 r}$ to the right of the fault point is obviously

$$
\dot{Z}_{0 r}{ }^{(1)}=\dot{Z}_{0 l i n}-\dot{Z}_{0}{ }^{(1)}+\dot{Z}_{0 s} \text {. }
$$

Here, for the first time, the zero sequence impedance of the system $\dot{Z}_{0 s}$ at the line's opposite side appears. For two-terminal lines, this quantity must be known a priori 
and written in the device memory. Now it remains to calculate the first approximation for zero sequence impedance to fault place $\dot{Z}_{0}{ }^{(1)}$. To do this, ratio $\dot{e}$ is introduced; its value is calculated using corresponding specific quantities:

$\dot{e}=\frac{\dot{Z}_{0 s p}}{X_{1 s p}}$.

Using (40), the last quantity necessary for determination of $\dot{I}_{f}^{(1)}$ can be found:

$\dot{Z}_{0}^{(1)}=\dot{e}^{(0)} X_{1 \text { ass }}{ }^{(0)}$

provided there is some initial value of the reactance to a fault place $\left(X_{\text {ass }}\right)$, assuming for the initial value, e.g., that the fault has occurred at the middle of the protected line; i.e. taking $X_{1 a s s}{ }^{(0)}=X_{1 \text { lin }} / 2$ we will obtain the first calculated value $X_{l}^{(1)}$. Taking the next assumed value of reactance to fault place $X_{\text {lass }}{ }^{(1)}$ we obtain value $X_{I}^{(2)}$ that is nearer to $X_{\text {lass }}^{(1)}$ than for the $X_{I}^{(1)}-X_{\text {lass }}^{(0)}$ pair. We should continue the iteration process, observing that in each step the obtained value approaches its assumed value until the desired precision is reached.

This way of proceeding ensures the convergence of iteration process in all cases, provided the calculation formulas correspond to the basic equation (10) when the true reactance to fault place inserted in (41) reflects on itself by (33).

The influence of variations in the specific active resistance is in an admissible range because the line load current is small as compared with the single phaseearth fault current. A $20 \% R_{c s p}$ variation against its value written in the protection device causes a $1-4 \%$ error of $\mathrm{X}_{l}$.

\section{THE CASE OF A DISTRIBUTION NETWORK}

The power lines of a distribution network are assumed to be radial, with no shield wires, hence the active resistance of a phase conductor for positive and zero sequence is the same (see Eq. (13)).

The $\dot{U}_{p h} ; \dot{I}_{p h}$ and $\dot{I}_{g}$ fault quantities are much smaller in these networks than those in grids with a direct earthed neutral. When a single-phase-earth fault occurs, the customers continue to receive electricity, and current $\dot{I}_{p h}$ is of the load current order, being therefore accurately measurable. Ground current $\dot{I}_{g}$ is equal to the output current of Ferranti's measuring transformer and therefore, despite its comparatively small value, can also be measured precisely enough. On the contrary, phase voltage $\dot{U}_{p h}$ is $1-2$ orders less than the rated value. In these circumstances, the precision of $\dot{Z}_{a}$ determination entirely depends on the accuracy of obtaining the $\dot{U}_{p h}$ value. We will leave the problem of measuring voltage $\dot{U}_{p h}$ to technicians. There is an additional peculiarity: the voltage drop on a fault resistance is comparable with the phase-to-earth voltage $\dot{U}_{p h}$. Therefore the apparent reactance $X_{a}$ to the fault place strongly differs from the direct sequence reactance $X_{1}$ to the 
fault place; this peculiarity can be successfully dealt with applying the apparent impedance method expounded in Sect. 2.

A simplified circuit diagram of the network with a phase-to-earth fault is shown in Fig. 3. The initial formulas for currents are the following:

$$
\begin{aligned}
& \dot{I}_{c s g}=3 j \omega C_{s g} \dot{E}_{p h} ; \quad \dot{I}_{c b f}=3 j \omega C_{b f} \dot{E}_{p h} ; \quad \dot{I}_{c^{\prime}}=3 j \omega C^{\prime} \dot{E}_{p h} ; \\
& \dot{I}_{c^{\prime \prime}}=3 j \omega C^{\prime \prime} ; \quad \dot{I}_{c}=\dot{I}_{c^{\prime}}+\dot{I}_{c^{\prime \prime}}=3 j \omega C \dot{E}_{p h} ; \quad C=C^{\prime}+C^{\prime \prime} ; \\
& \dot{I}_{c l i n}=\dot{I}_{c b f}+\dot{I}_{c} ; \quad \dot{I}_{L}=-j \frac{1}{\omega L_{c}} \dot{E}_{p h} ; \quad \dot{I}_{R}=\frac{1}{R} \dot{E}_{p h} ; \\
& \dot{I}_{F e}=\dot{I}_{c s g}+\dot{I}_{L}+\dot{I}_{R} ; \quad \dot{I}_{f}=\dot{I}_{F e}+\dot{I}_{c l i n} ; \quad \dot{I}_{g}=\dot{I}_{F e},
\end{aligned}
$$

where $\dot{I}_{c s g}$ is the capacitive phase-earth current of a sound part of the grid; $\dot{I}_{c}$ is the capacitive current of the faulty line in the span from substation to fault place $F$ (at the sought-for distance); $\dot{I}_{c l i n}$ is the capacitive current of the faulty line grid (a faulty line with other lines connected to it); $\dot{I}_{F e}$ is the output current of Ferranti's transformer; capacitances $C^{\prime}$ and $C^{\prime \prime}$ and corresponding currents $I^{\prime}{ }_{c}$ and $I^{\prime \prime}{ }_{c}$ are shown separately to stress their distributed nature and their influence on the voltage drop from the monitoring point to the fault place; $\dot{I}_{c s}$ is the symmetrical phase-tophase capacitive current in the span from the substation to fault place F (not represented in (42)); $\dot{I}_{f}$ is the current through the fault place; $\dot{I}_{g}$ is the current through ground at the sought-for distance; the other current designations are shown in Fig. 3. For calculation of capacitive currents, the specific capacitive currents $\dot{I}_{c s p}$ in $\mathrm{A} / \mathrm{km}$ can be used; then the formulas for their calculation become very simple:

$$
\dot{I}_{c s g}=j I_{c s p} l_{s g} ; \quad \dot{I}_{c}=j I_{c s p} l ; \quad \dot{I}_{c l i n}=j I_{c s p} l_{l i n},
$$

where $l_{s g}$ is the total length of sound (undamaged) lines of the grid; $l$ is the distance to the fault place; $l_{\text {lin }}$ is the total length of faulty line grid (all lengths in $\mathrm{km}$ ).

Currents $\dot{I}_{c s g} ; \dot{I}_{c b f} ; \dot{I}_{c} ; \dot{I}_{c l i n} ; \dot{I}_{L} ; \dot{I}_{R} ; \dot{I}_{f} ; \dot{I}_{F e}$ arise as a result of a single-phase earth fault. Besides, there are symmetrical capacitive phase currents resulting from phase-to-phase capacitances of a line. They are calculated applying specific symmetrical capacitive current $\dot{I}_{\text {cssp }}$ :

$$
\dot{I}_{c s}=j I_{c s s p} l ; \quad \dot{I}_{c s l i n}=j I_{c s s p} l_{l i n} .
$$

Faulty phase current $\dot{I}_{p h}$ is

$$
\dot{I}_{p h}=\dot{I}_{l o}+\dot{I}_{F e}+\dot{I}_{c l i n}+\dot{I}_{c s l i n} \text {. }
$$

Load current $\dot{I}_{l o}$ can be decomposed into symmetrical components $\dot{I}_{1 l o}, \dot{I}_{2 l o}$.

Due to the distributed nature of capacitive currents of a faulty line, on the span from Ferranti's transformer to fault place F, for phase voltage $\dot{U}_{p h}$ we cannot apply formula (10) without changing it. For $\dot{U}_{p h}$, taking into account that for the power line $\dot{Z}_{1}=\dot{Z}_{2}$, we should write:

$\dot{U}_{p h}=\left(\dot{I}_{1 l}+\Delta I_{1 c f}\right) \dot{Z}_{1}+\dot{I}_{2 l} \dot{Z}_{1}+\left(\dot{I}_{0 l}+\Delta \dot{I}_{0 c f}\right) \dot{Z}_{0}+\dot{I}_{f} R_{f}$. 


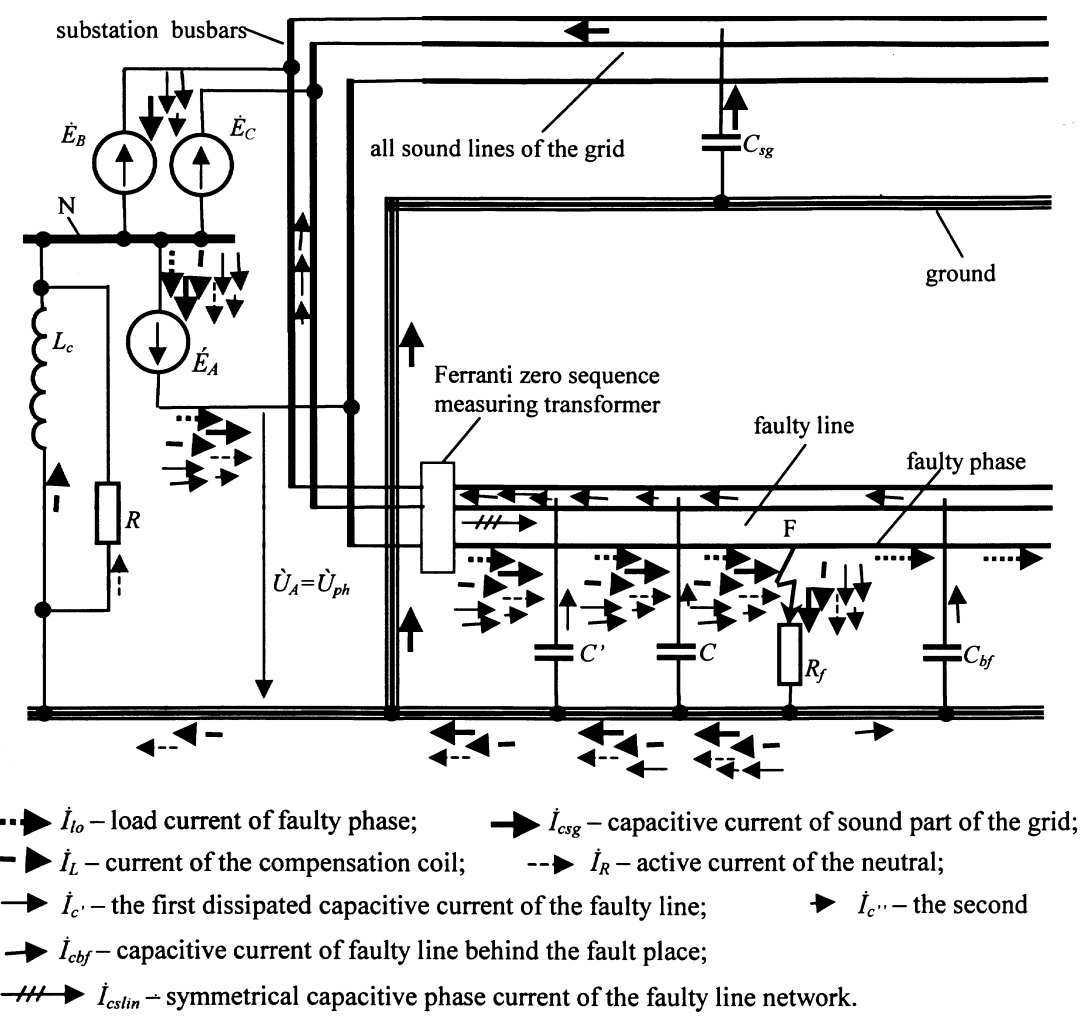

Fig. 3. Scheme of the grid with small phase-to-earth currents; the outlook of currents with phase-to-earth fault at point $\mathrm{F} ; \mathrm{N}$ - neutral of the grid; $\dot{E}_{A} ; \dot{E}_{B} ; \dot{E}_{C}-$ the phase $E M F \mathrm{~s}$, $\dot{E}_{p h}=\dot{E}_{A} ; U_{p h}$ - phase voltage of the faulty phase; $R_{f}$ - fault transient resistance

Currents $\Delta \dot{I}_{1 c f}$ and $\Delta \dot{I}_{0 c f}$ appear because of the distributed character of currents $\dot{I}_{c}$ and $\dot{I}_{c s}$ (see Fig. 3). The currents $\dot{I}_{p h}, \dot{I}_{1 l}, \dot{I}_{2 l}, \dot{I}_{0 l}$ can be measured and calculated out of three-phase currents or their constituent parts:

$$
\begin{aligned}
& \dot{I}_{p h}=\dot{I}_{1 l o}+\dot{I}_{2 l o}+\dot{I}_{c l i n}+\dot{I}_{c s l i n}+\dot{I}_{F e} ; \quad \dot{I}_{1 l}=\dot{I}_{1 l o}+\dot{I}_{1 c l i n}+\dot{I}_{c s l i n}+\frac{\dot{I}_{F e}}{3} ; \\
& \dot{I}_{2 l}=\dot{I}_{2 l o}+\dot{I}_{2 c l i n}+\frac{\dot{I}_{F e}}{3} ; \quad \dot{I}_{0 l}=\frac{\dot{I}_{F e}}{3} .
\end{aligned}
$$

We should determine currents $\dot{I}_{1 \text { clin }}$ and $\dot{I}_{2 c l i n}$ which appear as a result of capacitive current $\dot{I}_{c l i n}$ of the faulty line grid. From Fig. 4 we can determine that

$$
\begin{aligned}
& \dot{I}_{A}=\dot{I}_{c l i n} ; \quad \dot{I}_{B}=\left(-0.5-j \frac{\sqrt{3}}{6}\right) \dot{I}_{c l i n} ; \quad \dot{I}_{C}=\left(-0.5+j \frac{\sqrt{3}}{6}\right) \dot{I}_{c l i n} . \\
& \dot{I}_{1 \text { clin }}=\frac{1}{3}\left(\dot{I}_{A}+a \dot{I}_{B}+a^{2} \dot{I}_{C}\right)=\frac{2}{3} \dot{I}_{c l i n} ; \\
& \dot{I}_{2 \operatorname{clin}}=\frac{1}{3}\left(\dot{I}_{A}+a^{2} \dot{I}_{B}+a \dot{I}_{C}\right)=\frac{1}{3} \dot{I}_{c l i n} ; \quad \dot{I}_{0 \text { clin }}=\frac{1}{3}\left(\dot{I}_{A}+\dot{I}_{B}+\dot{I}_{C}\right)=0
\end{aligned}
$$




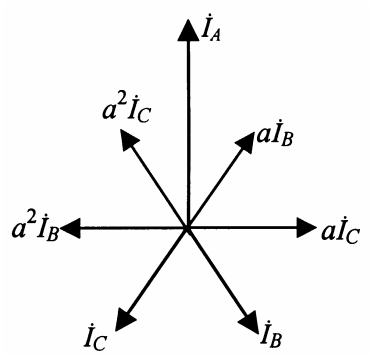

Fig. 4. Faulty phase capacitive currents.

In so doing, currents $\Delta \dot{I}_{1 c f}$ and $\Delta \dot{I}_{0 c f}$ are implicit (not measured). Their value may be estimated by their participation in the formation of phase voltage (46). Current $\Delta \dot{I}_{1 c f}$ consists of two constituents: $\Delta \dot{I}^{\prime}{ }_{1 c f}$ and $\Delta \dot{I}^{\prime \prime}{ }_{1 c f}$. Figure 4 explains the determination of current $\dot{I}_{c}$ (could not be confused with current $\dot{I}_{C}$ in phase $C$ ) flowing to the distance $l$ (from the protection device to the fault place) in phase $A$. Capacitive currents of phases $C$ and $B, \quad \dot{I}_{C}$ and $\dot{I}_{B}$, are represented as flowing with unchanged magnitude over the span $l$ (Figs. 3 and 4),

therefore:

$$
\dot{I}_{A}=\dot{I}_{c} ; \quad \dot{I}_{B}=\left(-0,5-j \frac{\sqrt{3}}{6}\right) \dot{I}_{c} ; \quad \dot{I}_{C}=\left(-0,5+j \frac{\sqrt{3}}{6}\right) \dot{I}_{c} .
$$

In reality, only the current in phase $\mathrm{A}, \dot{I}_{c}$, flows unchanged over span $l$. Currents in phases $B$ and $C$ (in accordance with (50)) near the fault place are close to zero. In the direction toward the protection device they grow linearly, and at the monitoring point their magnitude corresponds to Eq. (50). This is equivalent to the situation when in phases $B$ and $C$ currents $\Delta \dot{I}_{B}$ and $\Delta \dot{I}_{C}$, which are half of these currents determined by (50), flow in the opposite direction. Hence:

$$
\Delta \dot{I}_{A}=0 ; \quad \Delta \dot{I}_{B}=\left(0,25+j \frac{\sqrt{3}}{12}\right) \dot{I}_{c} ; \quad \Delta \dot{I}_{C}=\left(0,25-j \frac{\sqrt{3}}{12}\right) \dot{I}_{c},
$$

which gives:

$$
\Delta \dot{I}_{1 c f}{ }^{\prime}=\frac{1}{3}\left(\Delta \dot{I}_{A}+a \Delta \dot{I}_{B}+a^{2} \Delta \dot{I}_{C}\right)=-\frac{0,5}{3} \dot{I}_{c} .
$$

The current $\Delta \dot{I}^{\prime \prime}{ }_{1 c f}$ is calculated using symmetrical capacitive current $\dot{I}_{c s}$. The same considerations as in the case of $\Delta \dot{I}^{\prime}{ }_{1 c f}$ lead to the expression for this current:

$\Delta \dot{I}_{1 c f}^{\prime \prime}=-\frac{1}{2} \dot{I}_{c s}$.

Now current $\Delta \dot{I}_{1 c f}$ can be determined as

$\Delta \dot{I}_{1 c f}=\Delta \dot{I}_{1 c f}^{\prime}+\Delta \dot{I}_{1 c f}^{\prime \prime}=-\left(\frac{0.5}{3} \dot{I}_{c}+0.5 \dot{I}_{c s}\right)$.

Currents $\Delta \dot{I}_{2 c f}$ and $\Delta \dot{I}_{0 c f}$ are calculated using currents (51):

$$
\begin{aligned}
& \Delta \dot{I}_{2 c f}=\frac{1}{3}\left(\Delta \dot{I}_{A}+a^{2} \Delta \dot{I}_{B}+a \Delta \dot{I}_{C}\right)=0 ; \\
& \Delta \dot{I}_{0 c f}=\frac{1}{3}\left(\Delta \dot{I}_{A}+\Delta \dot{I}_{B}+\Delta \dot{I}_{C}\right)=\frac{0.5}{3} \dot{I}_{c} .
\end{aligned}
$$


Expression (46) for faulty phase voltage $\dot{U}_{p h}$ is not fit for the method expounded in Sect. 2, which is based on expression (10). The $\dot{U}_{p h}$ of expression (46) is to be divided into two parts:

$\dot{U}_{p h}=\dot{U}_{p h}^{\prime}+\Delta \dot{U}_{p h}$

with the first part:

$\dot{U}_{p h}^{\prime}=\left(\dot{I}_{1, l}+\dot{I}_{2, l}\right) \dot{Z}_{1}+\dot{I}_{0, l} \dot{Z}_{0}+\dot{k}_{f} \dot{I}_{p h} R_{f}=\dot{U}_{p h}-\Delta U_{p h} ;$

and the second one:

$\Delta \dot{U}_{p h}=\Delta \dot{I}_{1 c f} \dot{Z}_{1}+\Delta \dot{I}_{0 c f} \dot{Z}_{0}$.

After we have found the first part $\dot{U}_{p h}^{\prime}$ of the phase voltage $\dot{U}_{p h}$, the determination of $X_{l}$ and $R_{f}$, is the routine procedure described in Sect. 2.

To determine the distance to fault place $l$ precisely, we must know currents $\dot{I}_{c}$ and $\dot{I}_{c s}$, whereas for finding the latter ones it is necessary to know the distance $l$ to the fault place, which is the sought-for quantity. To break this vicious circle, the iterative calculations must be done. At the start, the initial distance $l^{(0)}$ to fault place must be assumed - this can be half the faulty line length. Applying the iteration process, which is similar to that for high voltage lines, the distance to fault place can be found. The iteration process converges fast. However, when specific resistance $R_{c}$ of phase conductor diverges from the value written in the device memory, the calculated distance to fault place changes significantly. The calculations have shown that for an unloaded power line the deviation of $R_{c s p}$ does not influence the results, while the results for a loaded line strongly depend on the ratio ground current/load current. The data acquired for $R_{c s p}=0.306 \Omega / \mathrm{km}$ are the following: for the ratio 0.12 the distance error is $50 \%$ at $\Delta R_{c s p}=20 \%$, and for the ratio 0.03 the distance error is $200 \%$. Obviously, such an outcome is unacceptable. An attempt was made to recalculate conductor resistance $R_{c s p}$ but it was unsuccessful, being based on expression (1) only. Indeed, to find the third unknown $R_{c s p}$ one more equation must be applied, however this equation requires one more measured quantity, which is impossible when only voltages and currents are measured at the monitoring point. Obtaining the temperature of phase conductor would solve the problem. The error drastically diminishes when Ferranti's transformer current (approximately equal to the fault current (see (42)) grows. Already at this current equaling half the load current satisfactory results appear. If the measures to reduce the influence of conductor active resistance inconsistency are taken, the distance to the fault place can be determined with a desirable precision.

To perform calculations, the line parameters $R_{c s p} ; R_{g s p} ; X_{1 s p} ; X_{0 s p}$ must be written in the device memory, $\dot{I}_{p h} ; \dot{I}_{g} ; \dot{U}_{p h}$ must be measured, and then $\dot{Z}_{1 s p} ; \dot{Z}_{0 s p}$; 
$\dot{K}_{N} ; \dot{k} ; a ; b ; c$ calculated. The iteration procedure starts with an assumed initial value of the distance to fault place $l_{\text {ass }}{ }^{(0)}$, which, for example, can be taken half the faulty line length.

The calculational algorithm could be presented as follows.

Perform the first iteration with $l=l_{\text {ass }}{ }^{(0)}$ according to the written formulas to find the quantities in the following sequence: $\dot{Z}_{1} ; \dot{Z}_{0} ; \dot{I}_{c} ; \dot{I}_{c s} ; \Delta \dot{I}_{1 c f} ; \Delta \dot{I}_{0 c f} ; \Delta \dot{U}_{p h}$; $\dot{U}_{p h} ; \dot{Z}_{a} ; \dot{I}_{c l i n} ; \dot{I}_{f} ; \dot{k}_{f} ; \dot{k}_{d X} ; \dot{k}_{d R} ; d^{\prime} ; d^{\prime \prime} ; h ; f^{\prime} ; f^{\prime \prime} ; \operatorname{tg} \varphi_{f} ; A ; C$ (for verification of preceding formulas); $R_{f} ; \mathrm{X}_{1}$; at the end, find $l^{(1)}$.

Do the second iteration with $l_{\text {ass }}{ }^{(1)}=l^{(1)}$ to receive $l^{(2)}$.

Continue in such a way putting the last calculated value of distance to fault place $l$ for the assumed value $l_{\text {ass }}$ of the next iteration until acceptable accuracy is attained. The results of iterative calculations converge fast.

\section{CONCLUSIONS}

1. The apparent impedance method for determination of the distance to singlephase earth fault can be applied to one-terminal and two-terminal high-voltage lines and to the radial lines of distribution networks.

2. This method involves the iteration procedure.

3. The instability of phase conductor resistance deserves special attention due to its unpredictable nature and wide range of deviations causing inadmissible errors in distribution networks. To deal with it, the wire temperature should be known at the fault initiation instant, otherwise the single-phase earth fault current is to be raised above the level of half the load current value.

\section{ACKNOWLEDGEMENTS}

I express my gratitude to RTU Prof. J. Rozenkrons and Ph D student $V$. Strelkovs for elucidating some questions concerning power line parameters.

\section{REFERENCES}

1. Lawrence, D. (Apr., 1988). Transmission line fault location using digital fault recorders. IEEE Transactions on Power Delivery 3 (2).

2. Novosel, D., Hart, D., Udren, E., Murari, M. (July, 1995). Fault location using digital relay data. $A B B$ Relays.

3. Sauhats, A., Jonins, A., Chuvychins, V., Danilova, M. (2001). Fault location algorithms for power transmission lines based on Monte-Carlo method. In IEEE Power Techn. Conf. Proceedings, Porto (Portugal).

4. Bogdashova, L., Kachesov, V. (2005). Parametric on-line fault location methods for distribution MV networks In IEEE St. Petersburg Power Techn. Conf. Proceedings St. Petersburg (Russia).

5. Srdjan Skok, Antev Marusic (2001). Distance protection of double circuit line based on Kohonen's neural network considering different operation modes In IEEE Power Techn. Conf. Proceedings, Porto (Portugal). 
6. Mazon, A.J. et al. (2001). Fault location system on double circuit two-terminal transmission lines based on ANN's In IEEE Power Techn. Conf. Proceedings, Porto (Portugal).

7. Survilo, J. (2004). "Visible" impedances of distance protection. Scientific proceedings of Riga technical university; Power and electrical engineering 13 (4), 41-52.

8. Survilo, J., Sauhats, A. (2005). The use of classical algorithm of phase-to-earth fault distance protection for determining the fault true impedances. Scientific Proceedings of Riga Technical University, Power and Electrical Engineering 14 (4), 146-157.

9. Survilo, J. (2006). Determining the single phase-to-earth fault impedances in parallel lines using distance protection classical algorithm Scientific Proceedings of Riga Technical University, Power and Electrical Engineering 16 (4), 41-51.

10. Survilo, J., Rozenkrons, J. (2006). Phase-to-earth fault distance protection for medium voltage grids Scientific Proceedings of Riga Technical University, Power and Electrical Engineering 17 (4), 117-123.

11. Survilo, J. (2006). Once more on single-terminal algorithms for location of power line faults Latv. J. Phys. Tech. Sci. (6), 15-23.

12. Fortescue, C. Fault analysis by the method of symmetrical components. www.yahoo.com/search? $\mathrm{p}=$ Fortescue + matrix

13. Survilo, J. (2007). Consideration of specific resistance of a conductor by the method of apparent impedance Scientific Proceedings of Riga Technical University, Power and Electrical Engineering 20 (4), 36-42.

\section{“REDZAMĀS PRETESTĪBAS” METODE}

\section{J. Survilo}

\section{Kopsavilkums}

Redzamo pretestību no vienfāzes īsslēguma ar zemi var aprēķināt, pielietojot distantaizsardzības klasisko algoritmu. Pateicoties šīs pretestības kompleksam raksturam, algoritma izteiksmi var sadalīt divos vienādojumos. Arī divus nezināmos - induktīvo pretestību līdz bojājuma vietai un bojājuma pretestību - var izrēķināt, ja bojātās fāzes spriegums un strāva kā arī zemes strāva vai līnijas nullsecības strāva ir zināmas. To var sasniegt, pateicoties īpašai matemātiskai procedūrai, kas šeit tika nosaukta par redzamās pretestības metodi. Izmantojot šo metodi, ir nepieciešams zināt īpatnējus līnijas parametrus. Augstsprieguma līnijām un sadales tīkla radiālajām līnijām mērḳi var sasniegt, pielietojot iteratīvos aprēķinus ar nosacījumu, ka pietiekoši precīzi ir izmērîts bojātās fāzes spriegums sadales tīklos. Starp citiem līnijas parametriem fāzes vada īpatnējās aktīiās pretestības main̄̄gums pelna īpašu uzmanību tās nenoteiktības un noviržu plašā diapazona dēḷ, kas noved pie nepieļaujamām kḷūdām sadales tīklos. Lai novērstu šo trūkumu, jāzina fāzes vada temperatūra vienfāzes zemesslēguma iestāšanās laikā. Ja to nevar izpildīt, tad jāpanāk, lai zemesslēguma strāva būtu lielāka par pusi no slodzes strāvas. 